\title{
EPS Scholarships
}

\section{Council Launches Scheme for 1978/79 Academic Year}

\section{EPS Scholarships for 1978-79}

As indicated in the report on the Helsinki meeting, Council has decided to launch the EPS Scholarship scheme immediately in order that the first physicists selected can begin their research in a new country from the autumn of this year. The main principles as approved by Council are set out below together with additional information presented as a series of questions and answers.

\section{How many scholarships are available?}

For this next year scholarships have been offered by the following countries :

\section{Italy : 10 scholarships}

Poland : 10 scholarships

Romania : 5 scholarships

Switzerland : 1 scholarship plus one additional in 1979/80.

Other countries have the question under study and hope to have answers for $79 / 80$.

To which institutions do the $78 / 79$ scholarships apply?

The full list is given in the table on page 4 together with supplementary provisions where applicable, and information on the fields of physics envisaged.

What do the Scholarships Cover ?

The offer from Italy comprises financial support of 300,000 Italian liras per month over a period of 9 months. In Poland the support is roughly equal to the salary earned by research associates at the universities. In Romania, the emoluments will be adjusted according to age and experience to cover out-of-pocket expenses. Those at the Magurele centre outside Bucharest will be accommodated on the campus. In Switzerland, a regular salary will be paid of between 1000 and $1500 \mathrm{Sw}$. Fr. per month dependending upon the candidate's experience.

\section{How are Candidates Selected?}

Selection is by a central committee of EPS but the final decision rests with the host institute. Some preference will be given to applicants from countries offering scholarships to encourage the notion of exchange but there is no direct relationship between offers and eligibility.

How can a candidate apply?

(a) If possible, the candidate (or his professor) should first make informal contact with the head of the department in which he would like to work. If this can readily be done and a direct line established between candidate and supervisor the following stages will be very much simplified. It is, however, recognized that it is not always possible to do this rapidly and the candidate may not know the relevant person with whom to get in touch.

(b) Formal application is made directly to the EPS Secretariat on a form which will be supplied on application. On this will be required full details of qualifications already obtained, activity currently being followed, specialization, centre of learning for which application is made etc. (c) From this point on, the case will be treated individually according to the arrangements already made with the area representatives.

By when must application be made?

The sooner that candidates can announce their intention of applying for a scholarship by requesting an application form the better. It would be useful if even at this stage, an outline could be given also of their interests. For an applicant to be certain of consideration, his application must be at the EPS Secretariat by June 30 . For the year $1979 / 80$, a new announcement will be made, but prospective candidates should be ready for the end of this year.

\section{Aims and Scope of the Programme as Agreed by Council.}

The aim of the EPS scholarship programme is to provide opportunities for advanced doctoral students or young post-doctoral fellows to undertake studies and research in European universities and research centres.

For this purpose correspondents are nominated by National Societies and Academies. These correspondents inform the European Physical Society on the availability of scholarships in their country and may also channel applications from nationals of their own country to scholarships offered in other countries. The scholarships available will be published each year in Europhysics News.

Eligibility

Scholarships handled in this programme are open to nationals of countries represented by a national organization in EPS, but not tenable in the candidate's own country.

Qualification

Candidates should be working towards a $\mathrm{PhD}$ or have possessed a PhD degree for not more than five years.

Length of Tenure

Scholarships handled in this programme have a normal duration of one year. However, in some cases this may be extended. The candidate who seeks an extension will be in competition with candidates for a new scholarship.

Material Organization

The scholarships are offered by national organizations or academies, or other organizations, and handled materially by them.

The stipend should be sufficient to cover living and study expenses for the whole year.

Travel costs may be included in the scholarships.

\section{Scientific Organization}

Together with the scolarships, the offering organization offers a list (not necessarily exhaustive) of universities and research institutes where the scholarships can be used.

The number of scholarships per country together with a list (not necessarily exhaustive) where the scholarships can be used is published every year in Europhysics News with a call for applications.

A direct contact between the candidate and the prospective host institute is established early, if possible by the candidate himself at the time of application. The applications are examined by a special EPS selection committee, which evaluates them with the help of leading European scientists. The final award of the fellowship is made after securing the acceptance of the candidate by the host institute.

The detailed scheme of collaboration is agreed between the parties involved in the programme. 